\title{
A Clinical study of high volume camp surgeries in a tertiary institute of central India
}

\author{
Chanchlani $\mathbf{M}^{1}$ \\ ${ }^{1}$ Dr Madhu Chanchlani, Assistant Professor, Department of Ophthalmology, Chirayu Medical College and Hospital, \\ Bhopal, MP, India
}

Address for Correspondence: Dr Madhu Chanchlani, Email: roshanchanchlani@gmail.com

\begin{abstract}
Background: Blindness is one of the significant social problems in India with 7 million of the total 45 million blind people in the world residing in our country. If there is no change in the current trend of blindness, the number of blind persons in India would increase to 31.6 million in 2020.Apart from health and status of vision, there are many other socioeconomic factors and perceptions, which influence the decision making of the people for getting operated for cataract. Productivity per individual surgeon/unit should be increased through a high volume, highquality cataract surgery approach to solve the problem of India's curable blindness. As we are working in a Medical college hospital with experienced surgeons performing surgeries by Phaco-emulsification and utilizing the technique of manual small incision cataract surgery,planned study is undertaken to evaluate the results in a systematic manner. Aims and objectives: To analyze the outcome of cataract surgeries in camps in terms of duration of surgery, visual acuity, complications and their management. Material and Methods: It was a hospital-based, descriptive study. 3000 study subjects were recruited from the Department of Ophthalmology Chirayu medical College, Hospital from cataract camps, during three year period from December 2010 to December 2014. Results: In our study Mature cataract was seen in $41.2 \%$ cases.Intra operative complications were graded according to OCTET grading and was accounting for $5.30 \%$. Post-operative complications seen in our study was mild iritis $2.90 \%$, severe iritis $2.28 \%$, transient corneal oedema $4.20 \%$, hypheama $1.17 \%$, hypopyon $0.40 \%$, residual cortex $1.20 \%$ and malposition of IOL seen in $3.30 \%$. Levels of visual acuity after cataract surgery were categorized using the WHO guidelines of good outcome being $6 / 6$ to $6 / 24$, borderline outcome as $6 / 24$ to $6 / 60$ and poor outcome as $<6 / 60$ In the present study, the majority $(89.5 \%)$ had a good outcome, $(8.5 \%)$ borderline, and (1.9)\% cases had poor outcome, which implies that the visual outcome was very good. Conclusion - The study shows that high volume camp surgery plays a commendable role in transferring majority of elderly rural Indian population from the category of the blind and dependant to a group that is visually rehabilitated, independent, mobile and socially productive. A good choice of surgical technique, trained surgeons and paramedical personnel and good organizational setup can provide good visual outcome and increases the productivity per individual surgeon/unit to control blindness in developing world.
\end{abstract}

Key words: Cataract Surgery, Eye Camp, Blindness Control

\section{Introduction}

$50-80 \%$ of the bilaterally blind patients in our country are due to cataract. It is reported that around 10 million operable cataract patients are there in India and only 5 million cataract surgeries are carried out [1]. Cataract surgeries with IOL implantation have to be performed in large scale to deal with this preventable cause of blindness. This problem can be solved by organising frequent cataract screening camps in rural areas and increasing productivity per individual surgeon/unit. The focus of this study is to analyse the visual outcome amongst patients operated in high volume camp surgery Manuscript received: $25^{\text {th }}$ Dec 2014 Reviewed: $30^{\text {th }}$ Dec 2014

Author Corrected: 27 Jan 2015 Accepted for Publication: $7^{\text {th }}$ Feb 2015 in a tertiary institute.

\section{Material and Methods}

Study design: It was a hospital-based, descriptive study of 3000 patients. The study subjects were recruited from the Ophthalmology department from community based cataract camps and transferred to Chirayu medical College, Hospital during December 2010 to December 2014. After Institutional Ethical Committee approval a retrospective study of 3000 cases meeting the inclusion and exclusion criteria were included for this study. Surgeons consistently performing more than 80 
surgeries per day in three operation theatres were defined as high volume surgeons.

Inclusion criteria: Mature cataract, Hyper-mature cataract, visually significant cataracts, Posterior subcapsular cataract, Nuclear sclerosis grade II-IV.

Exclusion criteria: Cataract with advanced Glaucomatous cupping, retinal pathology, complicated cataract, Pseudo Exfoliation syndrome, Subluxated, Paediatric and traumatic cataract, corneal opacity.

Methodology: All patients were admitted after noting history, local examination and relevant investigations were carried out by the expert doctors including slit lamp Biomicroscopy, tonometry, Fundus examination, and Keratometry and A-scan biometry.

Under all aseptic precaution, painting and draping was done. Local Peribulbar anaesthesia was given, Septidine
$(5 \%)$ eye drops were applied in conjunctival cul de sac. After Superior rectus bridle suture fornix based conjunctival flap was made. Site of incision was chosen according to preoperative keratometry reading. Depending on the technique size of incision ranged from 6 to $8 \mathrm{~mm}$, Side port was made with lance tip. Capsular staining was done with $0.5 \%$ Trypan blue. Continuous curvilinear capsulorhexis / can opener capsulotomy was done. Anterior chamber was entered with $3.2 \mathrm{~mm}$ keratome. Hydrodissection was done and nucleus prolapsed into AC and delivered out by viscoexpression/sandwitch technique. Remaining cortical matter was removed using irrigation-aspiration canula. A $6.0 \mathrm{~mm}$ optic, $12.5 \mathrm{~mm}$ overall diameter PMMA IOL was placed in-the-bag/sulcus. AC was formed. Subconjunctival injection of Dexamethasone and Gentamycin was given. Patients were examined on the 1 st post operative day, after 7 days and at the end of 6 week by the same surgeons. Refraction and spectacle correction was given at the end of 6 weeks.

\section{Results}

Table 1: Age wise distribution of patients

\begin{tabular}{|l|l|l|}
\hline Age in years & No. of Patients & Percentage (\%) \\
\hline $51-60$ & 512 & 17.06 \\
\hline $61-70$ & 1356 & 45.2 \\
\hline $71-80$ & 1132 & 37.73 \\
\hline Total & $\mathbf{3 0 0 0}$ & $\mathbf{1 0 0}$ \\
\hline
\end{tabular}

Table 2: Distribution of patients according to the type of cataract

\begin{tabular}{|l|l|l|}
\hline Type of cataract & No. of Patients & Percentage (\%) \\
\hline Mature Cataract & 1236 & 41.2 \\
\hline Nuclear cataract(grade II - IV) & 864 & 28.8 \\
\hline PSC & 578 & 19.2 \\
\hline Hypermature Cataract & 322 & 10.7 \\
\hline Total & $\mathbf{3 0 0 0}$ & $\mathbf{1 0 0}$ \\
\hline
\end{tabular}

Average duration of surgery: 5 min per case

Intra operative complications: were graded according to OCTET grading (Oxford cataract treatment Evaluation Team)

Grade I: unlikely to need operation or unlikely to head to a drop in visual acuity (VA) by 2 lines of Snellen chart or more.

Grade II: May need treatment or may lead to some loss of vision (by 2 lines or more) but not suddenly.

Grade III: Needs further treatment or needs emergency action; or leads to loss of VA by 2 lines or more; or leads to loss of VA by 2 lines or more if no emergency action is taken. 
Table 3: Intraoperative-Complications

\begin{tabular}{|l|l|l|l|}
\hline Intraoperative-Complications & OCTET Grading & No. of Patients & $\%$ \\
\hline Tunnel-related complication & I & 64 & 2.1 \\
\hline DM detachment & I & 34 & 1.1 \\
\hline Posterior capsular rent without vitreous loss & II & 46 & 1.5 \\
\hline Posterior capsular rent with vitreous loss & II & 12 & 0.4 \\
\hline Iridodialysis & I & 6 & 0.2 \\
\hline
\end{tabular}

Table 4: Post-operative complications:

\begin{tabular}{|l|l|l|l|}
\hline Complications & OCTET Grading & No. of Patients & $\%$ \\
\hline Mild Iritis & I & 89 & 2.9 \\
\hline Severe Iritis & II & 68 & 2.27 \\
\hline Transient Corneal oedema & I & 126 & 4.2 \\
\hline Small hyphaema & I & 35 & 1.17 \\
\hline Mild secondary Glaucoma & I & 72 & 2.4 \\
\hline Residual cortex & II & 36 & 1.2 \\
\hline Mild Hypopyon & I & 12 & 0.4 \\
\hline Vitreous in AC & II & 03 & 00.1 \\
\hline Cystoid Macular Oedema & II & 09 & 00.3 \\
\hline Malposition of IOL & II & 17 & 3.3 \\
\hline
\end{tabular}

Table 5: Visual Acuity at the end of 6 weeks:

\begin{tabular}{|l|l|l|}
\hline VA & No. of Patients & Percentage (\%) \\
\hline $6 / 6-6 / 24$ & 2126 & 70.8 \\
\hline $6 / 36-6 / 60$ & 562 & 18.7 \\
\hline$<6 / 60$ & 312 & 10.4 \\
\hline Total & $\mathbf{3 0 0 0}$ & $\mathbf{1 0 0}$ \\
\hline
\end{tabular}

Table 6: Best corrected visual Acuity at the end of 6 weeks:

\begin{tabular}{|l|l|l|}
\hline VA & No. of Patients & Percentage (\%) \\
\hline $6 / 6-6 / 24$ & 2686 & 89.5 \\
\hline $6 / 36-6 / 60$ & 256 & 08.5 \\
\hline$<6 / 60$ & 58 & 01.9 \\
\hline Total & $\mathbf{3 0 0 0}$ & $\mathbf{1 0 0}$ \\
\hline
\end{tabular}

\section{Discussion}

According to our study of 3000 cases, average duration of surgery was 5 minutes per case, a similar study conducted by Venkatesh et al shown average duration of the surgery was 3.75 minutes [3].
In our study intra operative complications were graded according to OCTET grading and was accounting for $5.30 \%$ which was higher in comparison to study done by Venkatesh et al[3]. Post-operative complications seen in 
our study was mild iritis $2.90 \%$, severe iritis $2.28 \%$, transient corneal oedema $4.20 \%$, hypheama $1.17 \%$, hypopyon $0.40 \%$, residual cortex $1.20 \%$ and malposition of IOL seen in $3.30 \%$. Post-operative complications were much higher in our study compared to the study done by Venkatesh et al. study[3].

The post-operative complications may cause discomfort and extended hospitalization which may lead to an overall poor surgical outcome and increase morbidity.

Venkatesh et al. used the OCTET grading and analyzed that 55 patients had Grade I, 19 patients (3.2\%) had Grade II, and 1 patient $(0.2 \%)$ had Grade III complications. In our study transient corneal edema (4.2 $\%$ was the commonest first POD complication, followed by mild iridocyclitis $(2.9 \%)$ like in the study by Desai $\mathrm{P}$ et al wherein the most common complication was corneal edema $(9.5 \%)$, followed by raised IOP (7.9 $\%)$ and uveitis (5.6\%) [4].

Severe iritis was treated with frequent use of topical steroids.

Patients with hypopyon received subconjunctival garamycin and dexamethsone along with frequent topical steroids.

In patients with haptic malposition, the intraocular lens was redialed and repositioned on the first postoperative day. Other complications resolved with routine postoperative medical therapy.

Fortunately no case of endophthalmitis was encountered in our study, wherein the incidence of endophthalmitis was very low $(0.03 \%)$ as mentioned by Kapoor et.al [5].

Visual outcomes for cataract surgery are reported as the achievement of a defined level of Snellen acuity $6 / 12$ or better in the operated eye at two points in time during the post-operative recovery process: at time of discharge from hospital and at the final refraction performed within 3 months of surgery.

Levels of visual acuity after cataract surgery were categorized using the WHO guidelines of good outcome being $6 / 6$ to $6 / 24$, borderline outcome as $6 / 24$ to $6 / 60$ and poor outcome as $<6 / 60$.

In the present study, the majority $(89.5 \%)$ had a good outcome, $(08.5 \%)$ borderline, and $1.9 \%$ cases had poor outcome, which implies that the visual outcome was very good and correlates well with the outcomes of various other studies $[3,4,6,7,8]$. Similarly Hennig et al. showed in his study that in $88 \%$ of eyes examined at a one-monthfollow-up visit, the vision achieved was $6 / 18$ or better with full aphakic correction, this corresponds with our study [9].

Even though the cataract surgical targets are being met, poor outcomes of cataract surgeries are a major problem in developing countries.

With the resolution of the corneal oedema and inflammation with time there was significant improvement in the visual acuity of the eyes 6 weeks after surgery compared to the visual acuity at discharge recorded at the first assessment.

\section{Conclusion}

The study shows that high volume camp surgery plays a commendable role in transferring majority of elderly rural Indian population from the category of the blind and dependant to a group that is visually rehabilitated, independent, mobile and socially productive.

A good choice of surgical technique, trained surgeons and paramedical personnel and good organizational setup can provide good visual outcome and increases the productivity per individual surgeon/unit.

\section{Funding: Nil}

Conflict of interest: None initiated.

Permission from IRB: Yes

\section{References}

1. Civerchia L, Ravindran RD, Apoorvananda SW, Ramakrishnan R, Balent A, Spencer MH, Green D..High-volume intraocular lens surgery in a rural eye camp in India. Ophthalmic Surg Lasers. 1996 Mar;27(3):200-8

2. Surka J, HussainS, Outcome of high volume cataract surgery at an academic hospital, S Afr Med J, 2001; 91:771-774.

3. Venkatesh R, Muralikrishnan R, Balent LC, Prakash SK, Prajna NV. Outcomes of high volume cataract surgeries in a developing country. $\mathrm{Br} J$ Ophthalmol. 2005 Sep;89(9):1079-83. 
4. Desai P, Minassian DC, Reidy A. National cataract surgery survey 1997-8: a report of the results of the clinical outcomes. J Ophthalmol,1999; 83(4):13361340 .

5. Kapoor H, Chatterjee A, Daniel R, Foster A. Evaluation of visual outcome of cataract surgery in an Indian eye camp. Br J Ophthalmol.1999;83(3):343-346.

6. Anand R, Gupta A, Ram J, Singh U, Kumar R. Visual outcome following cataract surgery in rural punjab. Indian J Ophthalmol. 2000; 48 (2):153-8
7. Bourne RRA, Dineen BP, Ali SM, Noorul Huq DM and Johnson GJ (2003). Outcomes of cataract surgery in Bangladesh: results from a population based nationwide survey. Br J Ophthalmol. 2003;87(7):813-9.

8. Malik AR, Qazi ZA and Gilbert C. Visual outcome after high volume cataract surgery inPakistan. $\mathrm{Br} \mathrm{J}$ Ophthalmol. 2003; 87(8):937-940.

9. Hennig A, Johnson G, Evans Jr et al. Long term clinical outcome of a randomised controlled trial of anterior chamber lenses after high volume intracapsular cataract surgery. Br J Ophthalmol. 2001 Jan;85(1):11-7..

\section{How to cite this article?}

Chanchlani M. A Clinical study of high volume camp surgeries in a tertiary institute of central India. Int J Med Res Rev 2015;3(2):157-161. doi: 10.17511/ijmrr.2015.i2.027. 